\title{
The Implications of the Conflict between Work and Family in Strain Levels: A Review Paper
}

\author{
Dionysia-Eleonora Ioannidi', Ioanna Nikolatou' ${ }^{1}$, Evangelia Sioula ${ }^{1}$, Michael Galanakis ${ }^{2}$, \\ George P. Chrousos ${ }^{1,3^{*}}$, Christina Darviri ${ }^{* \#}$ \\ ${ }^{1}$ Postgraduate Course Science of Stress and Health Promotion, School of Medicine, University of Athens, \\ Athens, Greece \\ ${ }^{2}$ Panteion University of Social and Political Sciences, Athens, Greece \\ ${ }^{3}$ First Department of Pediatrics, Children's Hospital Aghia Sofia, School of Medicine, University of Athens, \\ Athens, Greece \\ Email: "cdarviri@yahoo.com
}

Received 30 September 2015; accepted 12 July 2016; published 15 July 2016

Copyright (C) 2016 by authors and Scientific Research Publishing Inc.

This work is licensed under the Creative Commons Attribution International License (CC BY).

http://creativecommons.org/licenses/by/4.0/

(c) (7) Open Access

\begin{abstract}
During the last few decades researchers have developed an enormous interest in the interaction of the work and family domains. This paper is an attempt to review the recent literature and to categorize the various outcomes produced by the relationship between work and family as far as health is concerned.
\end{abstract}

Keywords

Work-Family Interface, Outcomes, Conflict, Strain

\section{Introduction}

Despite the fact that in the past work and family were considered to be unrelated to each other (Kanter, 1977), the growing empirical research has proven that this was just a myth (Edwards \& Rothbard, 2000; Greenhaus, Allen, \& Spector, 2006). At first look, this relationship between the two domains was believed to be strictly negative (Work-Family Conflict); nevertheless scholars have only recently argued that the work-family interface can also have a positive side (Work-Family Enrichment).

\footnotetext{
*These authors contributed equally and shared last authorship.

"Corresponding author.
}

How to cite this paper: Ioannidi, D.-E., Nikolatou, I., Sioula, E., Galanakis, M., Chrousos, G. P., \& Darviri, C. (2016). The Implications of the Conflict between Work and Family in Strain Levels: A Review Paper. Psychology, 7, 1138-1145. 
Many employees face the challenge of combining work and family roles. This can result in work-family conflict. The amount of these resources is fixed and thus the involvement in multiple roles results in the allocation of much greater resources to one role than the others (Rothbard, 2001; Greenhaus \& Powell, 2003). As a consequence, the individual's effectiveness in some life roles is being compromised (Greenhaus, Allen, \& Spector, 2006) and thus the experience of conflict between the work and the family domains is inevitable (Karatepe \& Bekteshi, 2008). Even though there is a vigorous area of research activity in recent decades, to the best of authors' knowledge there are not many recent articles that present the consequences of the work-family conflict in health. Thus, the main purpose of this paper is to focus on the work-family literature in order to identify the outcomes that derive from both the conflict and the facilitation process, and to propose areas that have not been given attention yet.

\section{Worklife Balance}

Greenhaus and Beutell (1985: p. 77) were the first who referred to the work-family conflict and defined it as "a form of inter-role conflict in which role pressures from the work and family domains are mutually incompatible in some respect", meaning that "participation in the work (family) role is made more difficult by virtue of participation in the family (work) role" (Van Steenbergen \& Ellemers, 2009; Kalliath, Hughes, \& Newcombe, 2012).

Despite the fact that, at first, researchers used to study only one direction of the conflict (work interference with family) (Cooke \& Rousseau, 1984; Bedeian et al., 1988), they soon realized that work-family conflict is a bidirectional phenomenon (Choi \& Kim, 2012; Kalliath, Hughes, \& Newcombe, 2012), and as such it consists of two dimensions, work-to-family (WTF) and family-to-work (FTW) (Frone, Russell, \& Cooper, 1992; Frone, Yardley, \& Markel, 1997; Zhao, Qu, \& Ghiselli, 2011). According to Netemeyer et al. (1996: p. 401), workfamily conflict (WFC) refers to "a form of inter-role conflict in which the general demands of, time devoted to, and strain created by the job interfere with performing family-related responsibilities", whereas family-work conflict (FWC) refers to "a form of inter-role conflict in which the general demands of, time devoted to, and strain created by the family interfere with performing work-related responsibilities” (Karatepe \& Bekteshi, 2008; Karatepe \& Kilic, 2009). The models assume, in particular, that job stressors and job involvement antecede WIF and family stressors and family involvement antecede FIW. Of particular importance for the present study, Frone et al. (1992) further proposed that WIF affects family distress and FIW is assumed to affect job distress. In contrast, effects of WIF on job distress and effects of FIW on family distress are not assumed.

\section{Implications of the Work-Family Conflict}

In a research conducted by Grice et al. (2011) it was investigated in which way the WFC and FWC are associated with the mental \& physical health of postpartum women in Minnesota. Results indicate that both directions of workfamily conflict are inversely associated with mental health scores, but no clear association was found between job spillover and physical health. The latter was examined in other studies as well, and the majority of the findings suggest that work-family conflict results in poor health (Greenhaus, Allen, \& Spector, 2006). However, Van Steenbergen and Ellemers (2009) in their research concluded that WFC is related to poorer scores on health outcomes, whereas FWC was not related to any of the health outcomes measured (cholesterol, body mass and physical stamina). In another study by Lallukka et al. (2010), the associations of work-family conflict and unhealthy behaviors among British, Finnish and Japanese employees, were explored. According to the findings, only few and inconsistent associations with unhealthy behaviors were observed. It was found for example that a positive relationship exists between work-family conflict and unhealthy food habits for women in Finland; work-family conflict was clearly associated with smoking but only among Finnish men and that workfamily conflict was related with drinking among women in Britain, but not in Japan (Lallukka et al., 2010). Moreover, as indicated in the literature, work-family conflict exacerbates exhaustion, both physical and emotional (Karatepe \& Uludag, 2007; Yanchus et al., 2010; Karatepe, 2010; Kalliath, Hughes, \& Newcombe, 2012). Besides, it is also positively linked to negative emotions such as depression, anxiety, resentment, frustration and even anger (Greenhaus, Allen, \& Spector, 2006), as well as to increased levels of psychological strain (Kalliath, Hughes, \& Newcombe, 2012).

Another area that it also appears to be strongly related to work-family conflict is sleep. More precisely, in a study by Lallukka et al. (2013) clear associations were detected between FWC and subsequent sleep medication 
among men, but not among women. Work-family conflict also produces various family-related outcomes. In their study Kalliath, Hughes and Newcombe (2012), exclaimed that work-family conflict is negatively related to the quality of the individual's relationship with his/her partner, as well as the quality of time spent with children, family and friends. Strazdins et al. (2013) focused on work-family conflict and its detrimental association to children's mental health. Cinamon, Weisel and Tzuk (2007) pointed out that WFC of one spouse has a positive relationship with FWC of the other spouse, while both dimensions of conflict (WFC and FWC) have a negative impact on the quality of parent-child interaction and parental self-efficacy. Finally, Cho and Allen's (2012) research results indicate that work-to-family conflict interferes with parent-child interactive behavior. More specifically, WFC has a significant negative impact on parent-child active activities, that is educational and recreational activities, but the findings for passive activities appear to be incongruent.

Over the last three decades, a multitude of studies have examined the relationship between work-family conflict and strain (Allen, Herst, Bruck, \& Sutton, 2000; Amstad, Meier, Fasel, Elfering, \& Semmer, 2011). Strains are the psychological, behavioral, and physiological reactions to environmental demands, threats, and challenges (i.e., stressors) and include responses such as burnout, depression, and headache (Ganster \& Rosen, 2013; Griffin \& Clarke, 2011). Although empirical evidence consistently supports positive correlations between both forms of work-family conflict and strain, certain controversies in the literature remain unresolved. There are researches that claim that the work-family conflict is a potential stressor that leads to various forms of strain. These arguments seem to have been based on Meijman and Mulder's (1998) effort-recovery (E-R) model (for an example, see Geurts, Kompier, Roxburgh, \& Houtman, 2003). According to the E-R model, exerting effort at work can result in negative load reactions, such as sleep problems and fatigue. The model further proposes that these negative load reactions are reversible through the process of recovery that occurs when the functional systems challenged during work go untaxed. However, when the individual is continuously exposed to these demands, no recovery can occur and psychobiological systems do not return to a baseline level. As a result, load reactions accumulate and may lead to longer term negative effects, such as impaired well-being. Through the lens of the E-R model, work-family conflict causes strain because it reduces opportunities for recovery in the family domain.

Except this model, there is the Hobfoll's (1989) COR theory. The theory proposes that individuals are motivated to gain or maintain resources, including "objects, personal characteristics, conditions, or energies that are valued by the individual or that serve as a means for attainment of these objects, personal characteristics, conditions or energies" (Hobfoll, 1989: p. 516).

But, there are argument suggesting that strain is likely to affect the perception and experience of work-family conflict. Kelloway et al. (1999) suggested that individuals with high strain undergo selective recall and attention, such that availability of negative thoughts and information is increased. Thus, distress is likely to affect the perceived frequency and intensity of difficulties of combining work and family roles.

Finally, there are arguments supporting that Work-family conflict and strain cause each other and typically refer to the notion of "loss spirals" as described in Hobfoll's (1989: p. 519) COR theory (for an example, see Demerouti et al., 2004). As explained above, this theory proposes that individuals strive to obtain and protect valued resources. When resources are initially lost, individuals become more vulnerable to future losses because replenishing and protecting resources requires the investment of other resources. That is, restoring one resource can deplete another resource. As a result, loss spirals can follow initial losses. This view would receive support if work-family conflict and strain predicted each other.

\section{Methodological Approach}

In order to find relevant articles, we used Scopus, the abstract and citation database of peer-reviewed literature. The term that has been employed as a key word was "work-family" along with (AND) the terms "outcomes", "consequences" and "meta-analysis", which they were used interchangeably, using English language restrictions. The first aim of the authors was to review articles published over the last five years, however the vast majority of the search results were studies focused only on facilitation, which did not serve the purpose of this paper. As a result, it was decided to extend the search to articles that have been published over the last decade, meaning that the publication dates would range from 2003-2013. Following this procedure 440 articles were identified. Only journals which fall into the categories of social sciences, psychology, business, management and accounting as well as decision sciences were admitted in the article selection phase. Finally, only 80 were selected be- 
cause these articles investigate the area of work-life balance from a duplication perspective. They include the two directions of conflict and facilitation together. Furthermore, only 45 articles were referred to specific work-family outcomes (Figure 1).

Search and selection were conducted independently by two separate researchers (D.I. and I.N.) qualified for research methodology issues. Classification of observational studies by design was performed independently by the two researchers. We used, in order to extract the data, the consort checklist scale, 2010.

\section{Results}

There are two important focal domains of adult life: work and family. However, the role expectations of work and family are not always compatible, which can create conflicts between work and family. Two directions have been identified for the inter-role conflict, including Work-Interference into Family (WIF) and Family Interference into Work (FIW). This is a reciprocal relationship in which work issues occur if the job obligations remain unfulfilled because one's family interferes with work. Consequently work issues interfere with family domain. Nevertheless, work family conflict is not limited to the two mentioned directions but it is also expanded to strain based inter role conflict. Work-family conflict is a potential stressor that leads to various forms of strain.

Results indicate that work family conflicts contribute to health-related problems and decreased quality of life. Work family conflicts are positively associated with general psychological strain, work and family related stress, somatic/physical symptoms and poor mental health. The majority of findings suggest that work-family conflict results in poor health and well-being. At the same time only few and inconsistent associations with unhealthy behaviors were observed.

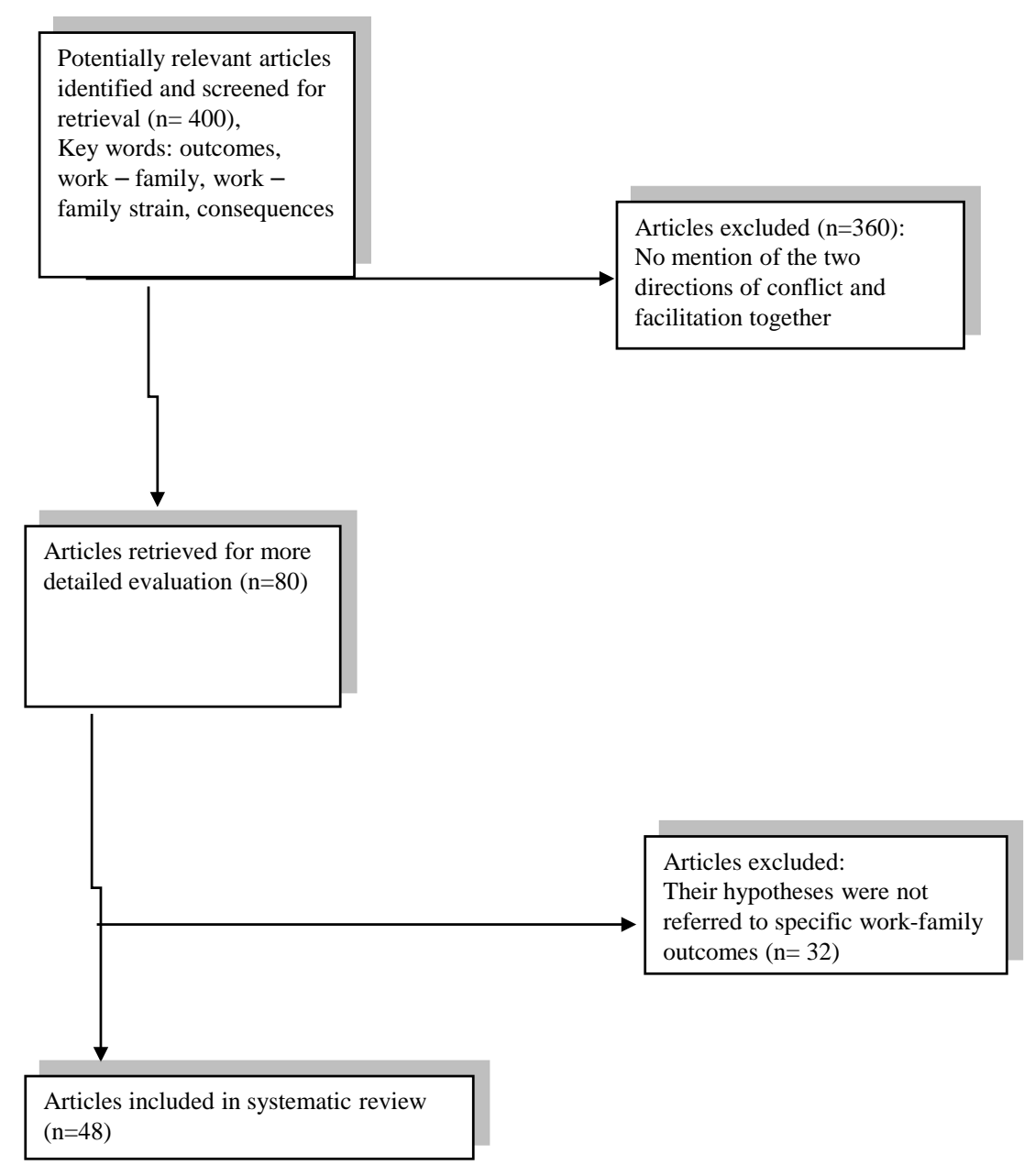

Figure 1. Flow diagram of screening process of articles. 
Both dimensions of conflict (WFC and FWC) have a negative impact on the quality of parent-child interaction and parental self-efficacy. The reciprocal relationships between WIF/FIW and strain held for both men and women.

In Allen et al.’s meta-analysis, work-family conflicts were negatively associated with life satisfaction and job and positively associated with general psychological strain, work and family-related stress, somatic/physical symptoms, depression, and burnout. Similar findings are reported in a more recent meta-analysis by Amstad et al. These researchers also considered the reciprocal relationship of family and work and assess three categories of potential outcomes: work-related outcomes, family-related outcomes, and domain-unspecific outcomes.

Results show that WIF and FIW are consistently related to all 3 types of outcomes. Both types of interrole conflict showed stronger relationships to same-domain outcomes than to cross-domain outcomes. Work-related outcomes such as work-related stress and organizational citizenship behavior were more strongly related to WIF, while family-related outcomes such as family satisfaction and family-related stress were more strongly associated with FIW. For both WIF and FIW, the strongest relationship was shown for domain-unspecific outcomes such as life satisfaction, health problems, psychological strain and stress.

Work family conflict exacerbates exhaustion both physical and emotional and is positively linked to negative emotions such as anxiety, depression, anger, frustration and resentment. WFC and FWC have positive relations with depressive symptoms and WFC have negative effects on psychological health. According to the results work family conflicts not only exert a direct effect but also have an indirect effect on depressive symptoms through inhibiting specific psychological responses.

Another area that it also appears to be strongly related to work family conflict is sleep as it can lead to an increase of sleep problems and sleep complaints. Despite the advances in examining the association between work family conflict and sleep quality and quantity, little is known about the effect of multi-dimensional construct of work family conflict on sleep. However, exerting effort at work can result in negative load reactions, such as sleep problems and fatigue.

\section{Discussion}

Most models in the work-family literature assume that work-family conflict influences strain but they don't recognize the influence of strain on work-family conflict. It has been made clear that the literature focuses on individual and work related outcomes produced by the work family role interaction. As there is evidence for the reciprocal relationships between both forms of work-family conflict and strain, existing models could be extended by taking into consideration these reciprocal effects. The association of both work-family conflict will be a promising avenue for future research.

It is also important to understand and examine why work-family conflict and strain are related. Although we know the direction of effect, we do not have the insights into the underlying mechanisms that are crucial for us to understand better the relationship between work-family conflict and strain. For that reason, we suggest that future research should address mediators in the above relationship.

The role of work-family conflict in other significant domains such as children's school performance, children's career choices and their beliefs about work could also be examined. Children's life satisfaction but also spouse life satisfaction could be another promising avenue for research. The work family conflict and the negative emotions, the psychological strain and on the other hand the emotional intelligence, the decision making, the sexual life and the individual's intention to marry and have children should also be examined in the sphere of work-family conflict.

In this review we tried to examine the direction of effect and the pattern of relationship between work-family conflict and strain. By including studies that used different time lags between the measurement waves, we found if the relationship between work and family conflict and strain depend on the length of the time lag. The reciprocal relationship of work-family conflict and strain according to our research can support conservation of resources theory (COR) notion of loss spirals and sheds light on the way these factors influence each other.

These results may contribute to prevention activities. Worksite interventions simultaneously considering both work and family characteristics may be most effective in reducing health risks. It is very important for practitioners in order to design organizational interventions targeted at improving employee's work-life balance and health. By reducing strain, organizations could help reduce work family conflict and ensure employees’ wellbeing. 
Interventional programs that help working people to reduce workplace stressor may also lead to better sleep quality. This could enhance employees' perceived organizational support and could be regarded as a resource that could cause positive work attitudes and outcomes and has positive effects on employee's mental health. In addition perceived organization support could affect job satisfaction, turnover intentions and depressive symptoms.

Mostly, work family research is based on cross-sectional studies. Consequently, future studies should address the longitudinal relationships of work family conflict with family related strain. Due to the fact that poor work life balance has been identified as one of the top emerging psychosocial health risks in the work force, longitudinal studies since they are relatively scarce, could shed light on health effects. Future research employing a longitudinal design and subject to lower selection biases is required to tease out the interrelationship between exposures such as family structure, work quality and work family interface and to point to the most appropriate policies to support employed persons. Additionally research on gender differences in health outcomes of WFC and FWC could shed light on the strength of the relations of WFC and FWC to health outcomes in men and women.

Regarding the present paper we should note that one research database was used in order to identify the reviewed articles. There may be studies published that have not been taken into consideration because only journals in the category of social sciences and psychology were admitted in the article selection phase.

\section{Conclusion}

In conclusion, there is evidence that Work Interference with Family (WIF) predicted strain and strain predicted work interference with family. Similarly, family interference with work and strain were reciprocally related. Family Interference with Work (FIW) predicted strain and strain predicted family interference with work. However, Work Interference with Family (WIF) had a stronger effect on work strain than did Family Interference with Work (FIW). It is important to understand and examine why work-family conflict and strain are related. Although we know the direction of effect, we do not have the insights into the underlying mechanisms that are crucial for us to understand better the relationship between work-family conflict and strain. For that reason, we suggest that future research should address mediators in the above relationship.

\section{References}

Allen, T. D., Herst, D. E. L., Bruck, C. S., \& Sutton, M. (2000). Consequences Associated with Work-to-Family Conflict: A Review and Agenda for Future Research. Journal of Occupational Health Psychology, 5, 278-308. http://dx.doi.org/10.1037/1076-8998.5.2.278

Amstad, F. T., Meier, L. L., Fasel, U., Elfering, A., \& Semmer, N. K. (2011). A Meta-Analysis of Work-Family Conflict and Various Outcomes with a Special Emphasis on Cross-Domain versus Matching-Domain Relations. Journal of Occupational Health Psychology, 16, 151-169. http://dx.doi.org/10.1037/a0022170

Bedeian, A. G., Burke, B. G., \& Moffett, R. G. (1988). Outcomes of Work-Family Conflict among Married Male and Female Professionals. Journal of Management, 14, 475-491. http://dx.doi.org/10.1177/014920638801400310

Cho, E., \& Allen, T. D. (2012). Relationship between Work Interference with Family and Parent-Child Interactive Behavior: Can Guilt Help? Journal of Vocational Behavior, 80, 276-287. http://dx.doi.org/10.1016/j.jvb.2011.12.002

Choi, H. J., \& Kim, Y. T. (2012). Work-Family Conflict, Work-Family Facilitation, and Job Outcomes in the Korean Hotel Industry. International Journal of Contemporary Hospitality Management, 24, 1011-1028. http://dx.doi.org/10.1108/09596111211258892

Cinamon, R. G., Weisel, A., \& Tzuk, K. (2007). Work-Family Conflict within the Family: Crossover Effects, Perceived Parent-Child Interaction Quality, Parental Self-Efficacy, and Life Role Attributions. Journal of Career Development, 34, 79-100. http://dx.doi.org/10.1177/0894845307304066

Cooke, R. A., \& Rousseau, D. M. (1984). Stress and Strain from Family Roles and Work-Role Expectations. Journal of Applied Psychology, 69, 251-262. http://dx.doi.org/10.1037/0021-9010.69.2.252

Demerouti, E., Bakker, A. B., \& Bulters, A. J. (2004). The Loss Spiral of Work Pressure, Work-Home Interference and Exhaustion: Reciprocal Relations in a Three-Wave Study. Journal of Vocational Behavior, 64, 131-149. http://dx.doi.org/10.1016/S0001-8791(03)00030-7

Edwards, J. R., \& Rothbard, N. P. (2000). Mechanisms Linking Work and Family: Clarifying the Relationship between Work and Family Constructs. Academy of Management Review, 25, 178-199.

Frone, M. R., Russell, M., \& Cooper, M. L. (1992). Antecedents and Outcomes of Work-Family Conflict: Testing a Model 
of the Work-Family Interface. Journal of Applied Psychology, 77, 65-78. http://dx.doi.org/10.1037/0021-9010.77.1.65

Frone, M. R., Yardley, J. K., \& Markel, K. S. (1997). Developing and Testing an Integrative Model of the Work-Family Interface. Journal of Vocational Behavior, 50, 145-167. http://dx.doi.org/10.1006/jvbe.1996.1577

Ganster, D. C., \& Rosen, C. C. (2013). Work Stress and Employee Health: A Multidisciplinary Review. Journal of Management, 39, 1085-1122. http://dx.doi.org/10.1177/0149206313475815

Geurts, S. A. E., Kompier, M. A. J., Roxburgh, S., \& Houtman, I. L. D. (2003). Does Work-Home Interference Mediate the Relationship between Workload and Well-Being? Journal of Vocational Behavior, 63, 532-559.

http://dx.doi.org/10.1016/S0001-8791(02)00025-8

Greenhaus, J. H., \& Powell, G. N. (2003). When Work and Family Collide: Deciding between Competing Role Demands. Organizational Behavior and Human Decision Processes, 90, 291-303. http://dx.doi.org/10.1016/S0749-5978(02)00519-8

Greenhaus, J. H., Allen, T. D., \& Spector, P. E. (2006). Health Consequences of Work-Family Conflict: The Dark Side of the Work-Family Interface. In P. L. Perrewé, \& D. C. Ganster (Eds.), Employee Health, Coping and Methodologies (pp. 6198). Emerald Group Publishing Limited. http://dx.doi.org/10.1016/s1479-3555(05)05002-x

Greenhaus, J. H., \& Beutell, N. J. (1985). Sources of Conflict between Work and Family Roles. Academy of Management Review, 10, 76-88.

Grice, M. M., McGovern, P. M., Alexander, B. H., Ukestad, L., \& Hellerstedt, W. (2011). Balancing Work and Family after Childbirth: A Longitudinal Analysis. Women's Health Issues, 21, 19-27. http://dx.doi.org/10.1016/j.whi.2010.08.003

Griffin, M. A., \& Clarke, S. (2011). Stress and Well-Being at Work. In S. Zedeck (Ed.), APA Handbook of Industrial and Organizational Psychology: Vol. 3. Maintaining, Expanding, and Contracting the Organization (pp. 359-397). Washington DC: American Psychological Association. http://dx.doi.org/10.1037/12171-010

Hobfoll, S. E. (1989). Conservation of Resources: A New Attempt at Conceptualizing Stress. American Psychologist, 44, 513-524. http://dx.doi.org/10.1037/0003-066X.44.3.513

Kalliath, P., Hughes, M., \& Newcombe, P. (2012). When Work and Family Are in Conflict: Impact on Psychological Strain Experienced by Social Workers in Australia. Australian Social Work, 65, 355-371.

http://dx.doi.org/10.1080/0312407X.2011.625035

Kanter, R. M. (1977). Work and Family in the United States: A Critical Review and Agenda for Research and Policy. New York: Russell Sage Foundation.

Karatepe, O. M. (2010). The Effect of Positive and Negative Work-Family Interaction on Exhaustion: Does Work Social Support Make a Difference? International Journal of Contemporary Hospitality Management, 22, 836-856. http://dx.doi.org/10.1108/09596111011063115

Karatepe, O. M., \& Bekteshi, L. (2008). Antecedents and Outcomes of Work-Family Facilitation and Family-Work Facilitation among Frontline Hotel Employees. International Journal of Hospitality Management, 27, 517-528. http://dx.doi.org/10.1016/j.ijhm.2007.09.004

Karatepe, O. M., \& Kilic, H. (2009). The Effects of Two Directions of Conflict and Facilitation on Frontline Employees’ Job Outcomes. The Service Industries Journal, 29, 977-993. http://dx.doi.org/10.1080/02642060902749716

Karatepe, O. M., \& Uludag, O. (2007). Conflict, Exhaustion, and Motivation: A Study of Frontline Employees in Northern Cyprus Hotels. International Journal of Hospitality Management, 26, 645-665.

http://dx.doi.org/10.1016/j.ijhm.2006.05.006

Kelloway, E. K., Gottlieb, B. H., \& Barham, L. (1999). The Source, Nature, and Direction of Work and Family Conflict: A Longitudinal Investigation. Journal of Occupational Health Psychology, 4, 337-346. http://dx.doi.org/10.1037/1076-8998.4.4.337

Lallukka, T., Arber, S., Laaksonen, M., Lahelma, E., Partonen, T., \& Rahkonen, O. (2013). Work-Family Conflicts and Subsequent Sleep Medication among Women and Men: A Longitudinal Registry Linkage Study. Social Science \& Medicine, 79, 66-75. http://dx.doi.org/10.1016/j.socscimed.2012.05.011

Lallukka, T., Chandola, T., Roos, E., Cable, N., Sekine, M., Kagamimori, S., Tatsuse, T., Marmot, M., \& Lahelma, E. (2010). Work-Family Conflicts and Health Behaviors among British, Finnish and Japanese Employees. International Journal of Behavioral Medicine, 17, 134-142. http://dx.doi.org/10.1007/s12529-009-9050-8

Meijman, T. F., \& Mulder, G. (1998). Psychological Aspects of Workload. In P. J. D. Drenth, H. Thierry, \& C. J. de Wolff (Eds.), Handbook of Work and Organizational: Vol. 2. Work Psychology (2nd ed., pp. 5-33). Hove, UK: Psychology Press.

Netemeyer, R. G., Boles, J. S., \& McMurrian, R. (1996). Development and Validation of Work-Family Conflict and Family-Work Conflict Scales. Journal of Applied Psychology, 81, 400-410. http://dx.doi.org/10.1037/0021-9010.81.4.400

Rothbard, N. P. (2001). Enriching or Depleting? The Dynamics of Engagement in Work and Family Roles. Administrative Science Quarterly, 46, 655-684. http://dx.doi.org/10.2307/3094827 
Strazdins, L., OBrien, L. V., Lucas, N., \& Rodgers, B. (2013). Combining Work and Family: Rewards or Risks for Children’s Mental Health? Social Science \& Medicine, 87, 99-107. http://dx.doi.org/10.1016/j.socscimed.2013.03.030

Van Steenbergen, E. F., \& Ellemers, N. (2009). Is Managing the Work-Family Interface Worthwhile? Benefits for Employee Health and Performance. Journal of Organizational Behavior, 30, 617-642. http://dx.doi.org/10.1002/job.569

Yanchus, N. J., Eby, L. T., Lance, C. E., \& Drollinger, S. (2010). The Impact of Emotional Labor on Work-Family Outcomes. Journal of Vocational Behavior, 76, 105-117. http://dx.doi.org/10.1016/j.jvb.2009.05.001

Zhao, X. R., Qu, H., Ghiselli, R. (2011). Examining the Relationship of Work-Family Conflict to Job and Life Satisfaction: A Case of Hotel Sales Managers. International Journal of Hospitality Management, 30, 46-54. http://dx.doi.org/10.1016/j.ijhm.2010.04.010

\section{Submit or recommend next manuscript to SCIRP and we will provide best service for you:}

Accepting pre-submission inquiries through Email, Facebook, Linkedin, Twitter, etc A wide selection of journals (inclusive of 9 subjects, more than 200 journals)

Providing a 24-hour high-quality service

User-friendly online submission system

Fair and swift peer-review system

Efficient typesetting and proofreading procedure

Display of the result of downloads and visits, as well as the number of cited articles

Maximum dissemination of your research work

Submit your manuscript at: http://papersubmission.scirp.org/ 